\title{
Rationally combining anti-VEGF therapy with radiation in NF2 schwannoma
}

\author{
Na Zhang ${ }^{1,2}$, Xing Gao ${ }^{1,3}$, Yingchao Zhao ${ }^{1,4}$, Meenal Datta ${ }^{1,5}$, Pinan Liv ${ }^{6}$ and Lei Xu ${ }^{1 *}$ \\ 'Department of Radiation Oncology, Massachusetts General Hospital and Harvard Medical School, Boston, Massachusetts 02114. \\ ${ }^{2}$ Department of Otolaryngology Head and Neck Surgery, Beijing TongRen Hospital, Capital Medical University, Beijing China, 100730. \\ ${ }^{3}$ Department of Oral and Maxillofacial Surgery, Xiangya Hospital, Central South University, Changsha, Hunan 410008, China. \\ ${ }^{4}$ Cancer Center, Union Hospital, Tongii Medical College, Huazhong University of Science and Technology, Wuhan, Hubei 430023, China. \\ ${ }^{5}$ Department of Chemical and Biological Engineering, Tufts University, Medford, MA 02155, USA. \\ ${ }^{6} \mathrm{Neural}$ Reconstructional Department, Beijing Neurosurgical Institute, Capital Medical University, Beijing, China, 100050.
}

Article Info

\section{Article Notes}

Received: August 29, 2016

Accepted: September 23, 2016

\section{${ }^{*}$ Correspondence:}

Dr. Lei Xu, Department of Radiation Oncology, Cox-7, Massachusetts General Hospital, Boston, Massachusetts 02114, Tel: 617-726-8051;

E-mail: lei@steele.mgh.harvard.edu

C 2016 Lei Xu. This article is distributed under the terms of the Creative Commons Attribution 4.0 International License.

\section{Keywords}

Neurofibromatosis type 2 (NF2)

Anti-VEGF therapy

Radiation therapy

Schwannoma

Tumor

\section{ABSTRACT}

Neurofibromatosis type 2 is characterized by bilateral vestibular schwannomas, which are benign tumors that originate from the nerve sheath and damage the nerve as they grow, causing neurological dysfunction such as hearing loss. Current standard radiation therapy can further augment hearing loss by inducing local damage to mature nerve tissue. Treatment with bevacizumab, a Vascular Endothelial Growth Factor (VEGF)specific antibody, is associated with tumor control and hearing improvement in NF2 patients; however, its effect is not durable and its mechanism of action on improving nerve function is unknown. Anti-VEGF treatment can normalize the tumor vasculature, improving vessel perfusion and delivery of oxygen. It is known that oxygen is a potent radiosensitizer; therefore, combining anti-VEGF treatment with radiation therapy can achieve better tumor control and allow for the use of lower radiation doses, thus minimizing treatment-related neurological toxicity.

\section{Current challenges in NF2 therapy}

Neurofibromatosis type 2 (NF2) is a dominantly inherited genetic condition with a birth prevalence of 1 in $25,000^{1}$. NF2 is characterized by bilateral vestibular schwannomas (VS), which are benign tumors composed of neoplastic Schwann cells that arise from the eighth cranial nerve, which transmits hearing and balance information from the ears to the brain. Although these vestibular schwannomas grow slowly, they usually lead to a significant or total hearing loss by young adulthood or middle age. The tumors can also compresses the brain stem, leading to headaches, difficulty swallowing, and other serious neurologic symptoms ${ }^{2}$. Standard approaches for the treatment of growing VS include surgical resection and radiation therapy (RT). While these tumors can be successfully removed or destroyed with surgery and radiation treatment, paradoxically, these therapeutic approaches can also cause hearing loss. For patients with sporadic VS who do not have NF2, RT is associated with long-term tumor control rates exceeding 95\%. However, hearing preservation rates after radiation range from $50-80 \%^{3,4}$. Post-RT outcomes for patients with NF2 are inferior to those for sporadic patients, with short-term local tumor control rates around $80-85 \%$ and hearing preservation rates less than $50 \%{ }^{3}$. Thus, the identification of a novel adjunct therapy to enhance radiosensitivity while minimizing toxicity-related hearing loss in VS is urgently needed. 


\section{Recent advances in targeted therapy for NF2}

Several previous investigations have suggested that - unlike other benign tumors - vestibular schwannomas, like malignant tumors, are able to induce the formation of new blood vessels. Vascular endothelial growth factor (VEGF) and its receptors (VEGFRs) are expressed in VS, and VEGF expression level positively correlates with schwannoma growth rate ${ }^{5-7}$. A 2009 New England Journal of Medicine study led by Scott Plotkin, MD, PhD, reported that treatment with bevacizumab, a humanized monoclonal antibody that specifically neutralizes VEGF-A, was associated with a reduction in the volume of most growing VS. More importantly, bevacizumab treatment improved hearing in 57\% patients ${ }^{7}$. Limitations of antiVEGF treatment - the fact that not all patients responded, that hearing improvement was often transient and the effect of anti-VEGF on nerve function is not known, and that some patients could not tolerate long-term bevacizumab treatment - indicated the need to better understand the mechanisms of anti-angiogenic therapy on the function of tumor-bearing nerves.

\section{Rationally combining anti-VEGF therapy with radiation}

Anti-VEGF agents were originally developed to block tumor growth by inhibiting blood vessel formation ${ }^{8,9}$. Bevacizumab has failed to improve survival benefit as a monotherapy in a number of tumors, but has been shown to confer survival benefit in combination with chemotherapy ${ }^{9}$. A potential explanation for the success of combined therapies is that bevacizumab "normalizes" the abnormal vasculature of tumors. It has been shown in many preclinical and clinical studies that anti-angiogenic therapy prunes tumor vessels and reverts the abnormal structure and function of the remaining vasculature toward a more normal state, abrogating its deleterious effects on the tumor microenvironment ${ }^{10}$. However, the normalization effect is transient - leading to a "normalization window" - during which the resulting vasculature is more normal, characterized by increased blood flow and improved delivery of concurrently administered anti-cancer drugs, as well as oxygen ${ }^{9}$. The addition of anti-angiogenic therapy to chemotherapy is now standard treatment for a variety of metastatic cancers including colorectal cancer and nonsquamous cell lung cancer.

Given the role of tissue oxygenation in tumor response to radiation, as well as the potential protective role of VEGF against endothelial cell apoptosis in response to radiation, several preclinical studies have demonstrated that antiangiogenic treatment potentiates the effects of radiation therapy against various solid tumors established from cell lines in xenograft models (Table 1). To date, early-phase clinical trials have demonstrated promising response rates and tolerability of combining bevacizumab with radiation for the local control of various primary, recurrent, and metastatic tumors (Table 2) ${ }^{11-14}$. These studies have

Table 1: Preclinical studies of combined anti-angiogenic and radiation therapy.

\begin{tabular}{|c|c|c|c|}
\hline Tumor & Cell line & Result & Reference \\
\hline NF2 Schwannoma & $\begin{array}{l}\text { HEI193 } \\
\text { NF2 }{ }^{--}\end{array}$ & $\begin{array}{l}\text { Enhanced tumor inhibition } \\
\text { Decreased dose of radiation } \\
\text { Improved neurological function }\end{array}$ & (20) \\
\hline \multirow[t]{2}{*}{ Glioblastoma } & U87 & $\begin{array}{l}\text { Enhanced tumor inhibition } \\
\text { Decreased dose of radiation }\end{array}$ & $(21-25)$ \\
\hline & U251 & $\begin{array}{l}\text { Enhanced tumor inhibition } \\
\text { Decreased dose of radiation }\end{array}$ & (24) \\
\hline Head and neck cancer & SCC1 & Enhanced tumor inhibition & (26) \\
\hline \multirow[t]{2}{*}{ Colorectal cancer } & LS174T & $\begin{array}{l}\text { Enhanced tumor inhibition } \\
\text { Reduced radioresistance }\end{array}$ & (21) \\
\hline & SW480 & Enhanced tumor inhibition & (27) \\
\hline Ovarian carcinoma & MA148 & Enhanced tumor inhibition & (28) \\
\hline Melanoma & B16F10 & Enhanced tumor inhibition & (28) \\
\hline \multirow[t]{3}{*}{ Lung cancer } & $54 \mathrm{~A}$ & Decreased dose of radiation & (23) \\
\hline & $\mathrm{H} 226$ & Enhanced tumor inhibition & (26) \\
\hline & A549 & $\begin{array}{l}\text { Enhanced tumor inhibition } \\
\text { Decreased dose of radiation }\end{array}$ & (29) \\
\hline
\end{tabular}


Table 2: Clinical trials of combined anti-angiogenic and radiation therapy.

\begin{tabular}{|c|c|c|c|c|c|c|c|}
\hline Tumor type & Phase & $\begin{array}{l}\text { Number of } \\
\text { Patients }\end{array}$ & $\begin{array}{l}\text { Radiation dose } \\
\text { /Fraction }\end{array}$ & $\begin{array}{c}\text { Bevacizumab } \\
\text { Dose }\end{array}$ & \multicolumn{2}{|c|}{ Outcome } & Reference \\
\hline \multicolumn{8}{|c|}{ CNS Tumor } \\
\hline nGBM & III & 978 & 60Gy/2Gy & $10 \mathrm{mg} / \mathrm{kg}$ & $\begin{array}{c}\text { Median PFS: } 10.7 \\
\text { months }\end{array}$ & $\begin{array}{c}\text { Median OS: } 15.7 \\
\text { months }\end{array}$ & $(\underline{30})$ \\
\hline nGBM & III & 921 & $60 \mathrm{~Gy} / 2 \mathrm{~Gy}$ & $10 \mathrm{mg} / \mathrm{kg}$ & $\begin{array}{l}\text { Median PFS: } 10.6 \\
\text { months }\end{array}$ & $\begin{array}{l}\text { Median OS: } 16.8 \\
\text { months }\end{array}$ & (31) \\
\hline nGBM & II & 70 & $60 \mathrm{~Gy} / 30$ & $10 \mathrm{mg} / \mathrm{kg}$ & PFS: $19.6 \%$ & OS: $13.6 \%$ & $(\underline{32})$ \\
\hline nGBM & II & 75 & $59.4 \mathrm{~Gy} / 33$ & $10 \mathrm{mg} / \mathrm{kg}$ & PFS: $21.2 \%$ & OS: $14.2 \%$ & $(\underline{33})$ \\
\hline nGBM & II & 125 & 50.4Gy/1.8Gy & $10 \mathrm{mg} / \mathrm{kg}$ & Median PFS: 13.8 months & 1-year PFS: $63.1 \%$ & (34) \\
\hline nGBM & ॥ & 68 & $60 \mathrm{~Gy} / 2 \mathrm{~Gy}$ & $10 \mathrm{mg} / \mathrm{kg}$ & Median PFS: 11.3 months & $\begin{array}{l}\text { Median OS: } 13.9 \\
\text { months }\end{array}$ & $(\underline{35})$ \\
\hline nGBM & II & 48 & $60 G y$ & $10 \mathrm{mg} / \mathrm{kg}$ & Median PFS: 9.2 months & $\begin{array}{l}\text { Median OS: } 13.2 \\
\text { months }\end{array}$ & $(\underline{36})$ \\
\hline rGBM & 1 & 25 & $30 \mathrm{~Gy} / 5$ & $10 \mathrm{mg} / \mathrm{kg}$ & PFS: $12.5-16.5 \%$ & OS: $7.3-7.5 \%$ & (37) \\
\hline rGBM & $1 / I I$ & 15 & $25 G y / 5$ & $10 \mathrm{mg} / \mathrm{kg}$ & Median PFS: 3.9 months & $\begin{array}{c}\text { Median OS: } 14.4 \\
\text { months }\end{array}$ & (38) \\
\hline \multicolumn{8}{|c|}{ Head and neck cancer } \\
\hline HNSCC & II & 30 & 56-70Gy/35 & $5 \mathrm{mg} / \mathrm{kg}$ & 3-year PFS: $61.7 \%$ & 3-year OS: $68.2 \%$ & $(\underline{39})$ \\
\hline HNSCC & 0 & 29 & 9.5-71.5Gy/1.25Gy & $10 \mathrm{mg} / \mathrm{kg}$ & 3-year PFS: $82 \%$ & 3 -year OS: $86 \%$ & $(\underline{40})$ \\
\hline HNSCC & II & 42 & 70Gy/2.12Gy & $15 \mathrm{mg} / \mathrm{kg}$ & 2-year PFS: 75.9\% & 2-year OS: $88 \%$ & (41) \\
\hline HNSCC & II & 78 & 70Gy/35 & $15 \mathrm{mg} / \mathrm{kg}$ & 2-year PFS: 75\% & 2-year OS: $88 \%$ & $(\underline{42})$ \\
\hline HNSCC & II & 30 & 70Gy/35 & $15 \mathrm{mg} / \mathrm{kg}$ & 2-year PFS: 88.5\% & 2-year OS: $92.8 \%$ & $(\underline{43})$ \\
\hline Nasopharyngeal & II & 46 & $70 \mathrm{~Gy} / 33$ & $15 \mathrm{mg} / \mathrm{kg}$ & 2-year PFS: $74.7 \%$ & 2-year OS: $90.9 \%$ & (44) \\
\hline \multicolumn{8}{|c|}{ Gastrointestinal cancer } \\
\hline Esophagus & II & 62 & 45Gy/1.8Gy & $15 \mathrm{mg} / \mathrm{kg}$ & pCR: $29 \%$ & & $(\underline{45})$ \\
\hline Colorectal & II & 32 & 45Gy/1.8Gy & $5 \mathrm{mg} / \mathrm{kg}$ & pCR: $25 \%$ & 4-year OS: 91\% & $(\underline{46})$ \\
\hline Rectal & ॥ & 66 & $50.4 \mathrm{~Gy} / 28$ & $5 \mathrm{mg} / \mathrm{kg}$ & $\begin{array}{l}\text { 1-year DFS: } 85 \% \\
\text { 2-year DFS: } 97 \%\end{array}$ & & (18) \\
\hline Rectal & 1 & 11 & $50.4 \mathrm{~Gy} / 28$ & $10-15 \mathrm{mg} / \mathrm{kg}$ & pCR: $18 \%$ & & $(\underline{14})$ \\
\hline Rectal & $1 / 11$ & 32 & $50.4 \mathrm{~Gy} / 28$ & $5-10 \mathrm{mg} / \mathrm{kg}$ & pCR: $16 \%$ & & $(\underline{13})$ \\
\hline Rectal & II & 25 & $50.4 \mathrm{~Gy} / 28$ & $5 \mathrm{mg} / \mathrm{kg}$ & pCR: $32 \%$ & & $(\underline{15})$ \\
\hline Rectal & II & 61 & $50.4 \mathrm{~Gy} / 28$ & $5 \mathrm{mg} / \mathrm{kg}$ & pCR: $13 \%$ & & (47) \\
\hline Rectal & II & 42 & $50.4 \mathrm{~Gy} / 28$ & $5 \mathrm{mg} / \mathrm{kg}$ & pCR: $18 \%$ & & $(\underline{12})$ \\
\hline Rectal & II & 59 & 45Gy/1.8Gy & $5 \mathrm{mg} / \mathrm{kg}$ & pCR: $36 \%$ & & $(\underline{48})$ \\
\hline Rectal & II & 91 & $45 \mathrm{~Gy} / 25$ & $5 \mathrm{mg} / \mathrm{kg}$ & pCR: $23.7 \%$ & & $(\underline{49})$ \\
\hline \multicolumn{8}{|c|}{ Gynecological cancer } \\
\hline Cervical & ॥ & 60 & $45 \mathrm{~Gy} / 25$ & $10 \mathrm{mg} / \mathrm{kg}$ & $\begin{array}{l}\text { No treatment-related } \\
\text { SAES }\end{array}$ & & $(\underline{50})$ \\
\hline Endometrial & II & 34 & $45 G y / 25$ & $5 \mathrm{mg} / \mathrm{kg}$ & 2-year PFS: 79.1\% & 2- year OS: $96.7 \%$ & (ㅁ1) \\
\hline Endometrial & \multirow{2}{*}{ II } & 15 & \multirow{2}{*}{$45 \mathrm{~Gy} / 25$} & \multirow{2}{*}{$10 \mathrm{mg} / \mathrm{kg}$} & 1-/3-year PFS: 80\%/67\% & $\begin{array}{c}\text { 1-/3-year OS: } \\
93 \% / 80 \%\end{array}$ & \multirow{2}{*}{$(\underline{52})$} \\
\hline Ovarian & & 4 & & & 1-/3-year PFS: 80\%/40\% & $\begin{array}{c}\text { 1-/3-year OS: } \\
100 \% / 60 \%\end{array}$ & \\
\hline
\end{tabular}

Abbreviations: CNS: central nervous system, nGBM: newly diagnosed glioblastoma, rGBM: recurrent GBM, MG: malignant glioma, HNSCC: head and neck squamous cell carcinoma, RT: radiation therapy, PFS: progression-free survival, OS: overall survival, SAEs: serious adverse events, pCR: pathologic complete response, SRS: stereotactic radiosurgery

found that some additional toxicities occur with the combination of bevacizumab, but common toxicities such as hypertension and proteinuria are generally easily managed while severe toxicities are rare. However, the reported response rate has varied, indicating the need for a rational pre-selection of patients for this combination treatment, as well as prospectively validated biomarkers of response $\mathrm{r}^{12,15-19}$. 
Combining anti-VEGF treatment with radiation therapy achieves better tumor control and minimizes radiation-related neurological damage in NF2-related schwannoma models

Although there are many reports in the context of malignant cancers, little is known of the effect of combined anti-VEGF treatment with radiation therapy in benign tumors. Recent studies led by Lei $\mathrm{Xu}, \mathrm{MD}, \mathrm{PhD}$, at Massachusetts General Hospital report that combining anti-VEGF treatment with radiation therapy improves the effectiveness of radiation treatment in NF2 related vestibular schwannoma models, and that the combination allows the use of a lower radiation dose to achieve the same degree of tumor control as a higher radiation dose without anti-VEGF therapy ${ }^{20}$. As a step further, this study shows that combining anti-VEGF treatment with radiation improves neurologic function by i) reducing the dose of radiation therapy and minimizing treatment-associated adverse effects, and ii) alleviating tissue edema, which may further improve neurologic function by decreasing muscle atrophy and increasing nerve regeneration ${ }^{20}$. This study provides compelling rationale and paves the road for testing combined anti-VEGF therapy with RT in NF2 related vestibular schwannomas. In preparation for future clinical studies with combined anti-angiogenic and RT, clinical studies of the therapeutic effects of anti-VEGF treatment on radiation-induced nerve damage need to be thoroughly examined. Furthermore, characterization of the schwannoma vasculature (including relative schwannoma vessel size and permeability, tumor contrast enhancement, edema-associated parameters from MRI), and biomarkers studies are needed to fully elucidate the normalization effect of bevacizumab in NF2 patients, and are needed before clinical studies with combined anti-angiogenic and RT can be designed.

\section{Funding Sources}

This study was supported by Department of Defense New Investigator Award (L.X.), American Cancer Society Research Scholar Award (L.X.), Ira Spiro Award (L.X.), NIH - P01CA080214, P50CA165962 and Outstanding Investigator Grant R35CA197743, and National Heart, Lung, And Blood Institute of the National Institutes of Health F31 Fellowship (F31HL126449, D.M.).

\section{References}

1. Evans DG, et al. A clinical study of type 2 neurofibromatosis. Q J Med. 1992; 84(304):603-618.

2. Plotkin SR, Merker VL, Muzikansky A, Barker FG $2^{\text {nd }}$, Slattery W $3^{\text {rd }}$. Natural history of vestibular schwannoma growth and hearing decline in newly diagnosed neurofibromatosis type 2 patients. Otol Neurotol. 2014; 35(1):e50-56.

3. Ammoun S, Hanemann CO. Emerging therapeutic targets in schwannomas and other merlin-deficient tumors. Nat Rev Neurol. 2011; 7(7):392-399.
4. Plotkin SR, et al. Bevacizumab for progressive vestibular schwannoma in neurofibromatosis type 2: a retrospective review of 31 patients. Otol Neurotol. 2012; 33(6):1046-1052.

5. Brieger J, Bedavanija A, Lehr HA, Maurer J, Mann WJ. Expression of angiogenic growth factors in acoustic neurinoma. Acta Otolaryngol. 2003; 123(9):1040-1045.

6. Caye-Thomasen P, Baandrup L, Jacobsen GK, Thomsen J, Stangerup SE. Immunohistochemical demonstration of vascular endothelial growth factor in vestibular schwannomas correlates to tumor growth rate. Laryngoscope. 2003; 113(12):2129-2134.

7. Plotkin SR, et al. Hearing improvement after bevacizumab in patients with neurofibromatosis type 2. N Engl J Med. 2009; 361(4):358-367.

8. Carmeliet P, Jain RK. Molecular mechanisms and clinical applications of angiogenesis. Nature. 2011; 473(7347):298-307.

9. Goel S, et al. Normalization of the vasculature for treatment of cancer and other diseases. Physiol Rev. 2011; 91(3):1071-1121.

10. Jain RK Antiangiogenesis strategies revisited: from starving tumors to alleviating hypoxia. Cancer Cell. 2014; 26(5):605-622.

11. Landry JC, et al. Phase 2 study of preoperative radiation with concurrent capecitabine, oxaliplatin, and bevacizumab followed by surgery and postoperative 5-fluorouracil, leucovorin, oxaliplatin (FOLFOX), and bevacizumab in patients with locally advanced rectal cancer: ECOG 3204. Cancer. 2013; 119(8):1521-1527.

12. Kennecke $\mathrm{H}$, et al. Pre-operative bevacizumab, capecitabine, oxaliplatin and radiation among patients with locally advanced or low rectal cancer: a phase II trial. Eur J Cancer. 2012; 48(1):37-45.

13. Willett CG, et al. A safety and survival analysis of neoadjuvant bevacizumab with standard chemoradiation in a phase I/II study compared with standard chemoradiation in locally advanced rectal cancer. Oncologist. 2010; 15(8):845-851.

14. Czito BG, et al. Bevacizumab, oxaliplatin, and capecitabine with radiation therapy in rectal cancer: Phase I trial results. Int J Radiat Oncol Biol Phys. 2007; 68(2):472-478.

15. Crane $\mathrm{CH}$, et al. Phase II trial of neoadjuvant bevacizumab, capecitabine, and radiotherapy for locally advanced rectal cancer. Int J Radiat Oncol Biol Phys. 2010; 76(3):824-830.

16. Nogue M, et al. Addition of bevacizumab to XELOX induction therapy plus concomitant capecitabine-based chemoradiotherapy in magnetic resonance imaging-defined poor-prognosis locally advanced rectal cancer: the AVACROSS study. Oncologist. 2011; 16(5):614-620.

17. Resch G, et al. Preoperative treatment with capecitabine, bevacizumab and radiotherapy for primary locally advanced rectal cancer--a two stage phase II clinical trial. Radiother Oncol. 2012; 102(1):10-13.

18. Spigel DR, et al. Phase II study of bevacizumab and chemoradiation in the preoperative or adjuvant treatment of patients with stage II/III rectal cancer. Clin Colorectal Cancer. 2012; 11(1):45-52.

19. Willett CG, et al. Surrogate markers for antiangiogenic therapy and dose-limiting toxicities for bevacizumab with radiation and chemotherapy: continued experience of a phase I trial in rectal cancer patients. J Clin Oncol. 2005; 23(31):8136-8139.

20. Gao X, et al. Anti-VEGF treatment improves neurological function and augments radiation response in NF2 schwannoma model. Proc Natl Acad Sci U S A. 2015; 112(47):14676-14681.

21. Lee CG, et al. Anti-Vascular endothelial growth factor treatment augments tumor radiation response under normoxic or hypoxic conditions. Cancer Res. 2000; 60(19):5565-5570.

22. Winkler $F$, et al. Kinetics of vascular normalization by VEGFR2 blockade governs brain tumor response to radiation: role of oxygenation, angiopoietin-1, and matrix metalloproteinases. Cancer Cell. 2004; 6(6):553-563. 
23. Kozin SV, et al. Vascular endothelial growth factor receptor-2-blocking antibody potentiates radiation-induced long-term control of human tumor xenografts. Cancer Res. 2001; 61(1):39-44.

24. Grossman R, et al. Combination of anti-VEGF therapy and temozolomide in two experimental human glioma models. Neurooncol. 2014; 116(1):59-65.

25. Buckel L, et al. Combination of fractionated irradiation with antiVEGF expressing vaccinia virus therapy enhances tumor control by simultaneous radiosensitization of tumor associated end othelium. Int J Cancer. 2013; 133(12):2989-2999.

26. Hoang T, Huang S, Armstrong E, Eickhoff JC, Harari PM. Enhancement of radiation response with bevacizumab. J Exp Clin Cancer Res. 2012; 31:37.

27. Hess C, et al. Effect of VEGF receptor inhibitor PTK787/ZK222584 [correction of ZK222548] combined with ionizing radiation on endothelial cells and tumour growth. Br J Cancer. 2001; 85(12):20102016.

28. Dings RP, et al. Scheduling of radiation with angiogenesis inhibitors anginex and Avastin improves therapeutic outcome via vessel normalization. Clin Cancer Res. 2007; 13(11):3395-3402.

29. Koo HJ, et al. Synergistic Effect of Anti-Angiogenic and Radiation Therapy: Quantitative Evaluation with Dynamic Contrast Enhanced MR Imaging. PLoS One. 2016; 11(2):e0148784.

30. Gilbert MR, et al. A randomized trial of bevacizumab for newly diagnosed glioblastoma. N Engl J Med. (2014) 370(8):699-708.

31. Chinot OL, et al. Bevacizumab plus radiotherapy-temozolomide for newly diagnosed glioblastoma. N Engl J Med. 2014; 370(8):709-722.

32. Lai A, et al. Phase II study of bevacizumab plus temozolomide during and after radiation therapy for patients with newly diagnosed glioblastoma multiforme. J Clin Oncol. 2011; 29(2):142-148.

33. Narayana A, et al. A clinical trial of bevacizumab, temozolomide, and radiation for newly diagnosed glioblastoma. J Neurosurg. 2012; 116(2):341-345.

34. Vredenburgh JJ, et al. Addition of bevacizumab to standard radiation therapy and daily temozolomide is associated with minimal toxicity in newly diagnosed glioblastoma multiforme. Int J Radiat Oncol Biol Phys. 2012; 82(1):58-66.

35. Hainsworth JD, et al. Phase II study of concurrent radiation therapy, temozolomide, and bevacizumab followed by bevacizumab/ everolimus as first-line treatment for patients with glioblastoma. Clin Adv Hematol Oncol. 2012; 10(4):240-246.

36. Raizer JJ, et al. A phase II study of bevacizumab and erlotinib after radiation and temozolomide in MGMT unmethylated GBM patients. J Neurooncol. 2016; 126(1):185-192.

37. Gutin PH, et al. Safety and efficacy of bevacizumab with hypofractionated stereotactic irradiation for recurrent malignant gliomas. Int J Radiat Oncol Biol Phys. 2009; 75(1):156-163.

38. Cabrera AR, et al. Concurrent stereotactic radiosurgery and bevacizumab in recurrent malignant gliomas: a prospective trial. Int J Radiat Oncol Biol Phys. 2013; 86(5):873-879.

39. Yao M, et al. Phase II study of bevacizumab in combination with docetaxel and radiation in locally advanced squamous cell carcinoma of the head and neck. Head Neck. 2015; 37(11):1665-1671.

40. Yoo DS, et al. Prospective trial of synchronous bevacizumab, erlotinib, and concurrent chemoradiation in locally advanced head and neck cancer. Clin Cancer Res. 2012; 18(5):1404-1414.

41. Fury MG, et al. A phase 2 study of bevacizumab with cisplatin plus intensity-modulated radiation therapy for stage III/IVB head and neck squamous cell cancer. Cancer. 2012; 118(20):5008-5014.

42. Argiris A, et al. Phase II randomized trial of radiation therapy, cetuximab, and pemetrexed with or without bevacizumab in patients with locally advanced head and neck cancer. Ann Oncol. 2016; 27(8):1594-1600.

43. Fury MG, et al. Phase II trial of bevacizumab + cetuximab + cisplatin with concurrent intensity-modulated radiation therapy for patients with stage III/IVB head and neck squamous cell carcinoma. Head Neck. 2016; 38 Suppl 1:E566-570.

44. Lee NY, et al. Addition of bevacizumab to standard chemoradiation for locoregionally advanced nasopharyngeal carcinoma (RTOG 0615): a phase 2 multi-institutional trial. Lancet Oncol. 2012; 13(2):172-180.

45. Bendell JC, et al. A phase II trial of preoperative concurrent chemotherapy/radiation therapy plus bevacizumab/erlotinib in the treatment of localized esophageal cancer. Clin Adv Hematol Oncol. $2012 ; 10(7): 430-437$.

46. Schrag D, et al. Neoadjuvant chemotherapy without routine use of radiation therapy for patients with locally advanced rectal cancer: a pilot trial. J Clin Oncol. 2014; 32(6):513-518.

47. Velenik V, et al. Neoadjuvant capecitabine, radiotherapy, and bevacizumab (CRAB) in locally advanced rectal cancer: results of an open-label phase II study. Radiat Oncol. 2011; 6:105.

48. Verstraete $\mathrm{M}$, et al. Combining bevacizumab and chemoradiation in rectal cancer. Translational results of the AXEBeam trial. Br J Cancer. 2015; 112(8):1314-1325.

49. Borg C, et al. Pathological response and safety of two neoadjuvant strategies with bevacizumab in MRI-defined locally advanced T3 resectable rectal cancer: a randomized, noncomparative phase II study. Ann Oncol. 2014; 25(11):2205-2210.

50. Schefter TE, et al. A phase II study of bevacizumab in combination with definitive radiotherapy and cisplatin chemotherapy in untreated patients with locally advanced cervical carcinoma: preliminary results of RTOG 0417. Int J Radiat Oncol Biol Phys. 2012; 83(4):1179-1184.

51. Viswanathan AN, et al. NRG Oncology/RTOG 0921: A phase 2 study of postoperative intensity-modulated radiotherapy with concurrent cisplatin and bevacizumab followed by carboplatin and paclitaxel for patients with endometrial cancer. Cancer. 2015; 121(13):2156-2163.

52. Viswanathan AN, et al. A prospective feasibility study of radiation and concurrent bevacizumab for recurrent endometrial cancer. Gynecol Oncol. 2014; 132(1):55-60. 